\title{
ANÁLISE DO USO E OCUPAÇÃO DO SOLO DA BACIA DO CÓRREGO ÁGUA VERMELHA, MUNICÍPIO DE UBERLÂNDIA-MG, POR MEIO DO SOFTWARE LIVRE QGIS
}

\author{
Aline de Freitas Roldão ${ }^{(a)}$, Eduardo Petrucci ${ }^{(b)}$, Francielle de Siqueira Castro ${ }^{(c)}$ \\ (a) Instituto de Geografia, Universidade Federal de Uberlânida, alineroldao@yahoo.com.br \\ (b) Instituto de Geografia, Universidade Federal de Uberlânida,_eduardo11sp@ hotmail.com \\ (c) Instituto de Geografia, Universidade Federal de Uberlânida, franciellesiqueiracastro@gmail.com
}

Eixo: GEOTECNOLOGIAS E MODELAGEM ESPACIAL EM GEOGRAFIA FÍSICA

\begin{abstract}
Resumo
A partir dos avanços tecnológicos tornou-se possível, através do geoprocessamento, adquirir informações de um alvo sem necessariamente estar em contato direto com ele. Essa popularização das geotecnologias tem nos últimos anos alcançado expressivos progressos, graças ao desenvolvimento e disponibilização de softwares livres, como o Quantum Gis (Qgis), garantindo maior arcabouço de análise aos estudos ambientais. Por efeito, o presente trabalho tem como objetivo a análise do uso e ocupação do solo da bacia hidrográfica do Córrego Água Vermelha, localizada no município de Uberlândia-MG. Por meio de imagem do Satélite Sentinel-2 e ferramentas do software livre Qgis, foi possível delimitar as feições do uso do solo e classificá-las. As análises apontam que o uso predominante na bacia é agricultura com $52,1 \%$ do total seguido pela pastagem que manifesta em $40,5 \%$ da área, subsidiados, em grande parte, pela morfologia do terreno. Os 7,3\% restantes representam a vegetação ciliar e edificações.
\end{abstract}

Palavras chave: Geotecnologias; Uso e ocupação do solo; Qgis; Córrego Água Vermelha; Uberlândia-MG.

\section{Introdução}

As Geotecnologias são importantes ferramentas que proporcionam a coleta, análise e divulgação de informações e dados espaciais. Com o advento da informática e desenvolvimento de equipamentos avançados na área da computação, Geodésia, satélites orbitais, as geotecnologias têm sido aprimoradas e são fundamentais aos planejadores e gestores do espaço, servindo como subsídio para os tomadores de decisão. Os Sistemas de Informação Geográfica - SIG (ou GIS - Geographic Information System), juntamente com a cartografia digital, sensoriamento remoto, sistemas de posicionamento global (GPS), são partes constituintes das geotecnologias.

GIS é um conjunto de ferramentas computacionais composto de equipamentos e programas que, por meio de técnicas, integra dados, pessoas e instituições, de forma a tornar possível a coleta, o armazenamento, o processamento, a análise e a oferta de informação georreferenciada produzida por meio de aplicações disponíveis, que visam maior facilidade, segurança e agilidade nas atividades humanas referentes ao 
monitoramento, planejamento e tomada de decisão relativas ao espaço geográfico (ROSA, 2005, p. 81).

O homem domina o meio ambiente e o transforma conforme as suas necessidades, sendo que, as atividades econômicas são uma das principais atividades de modificação da paisagem natural. Entretanto,

os demais tipos de uso têm a capacidade de transformação dos sistemas que compõem o meio. A adoção da Bacia Hidrográfica como unidade territorial de planejamento, pela Lei 9.433, de 8 de janeiro de 1997, que institui a Política Nacional de Recursos Hídricos, fez com que a bacia hidrográfica e suas sub-bacias sejam consideradas em sua totalidade, como um sistema ambiental aberto. Cunha (2006) elucida que a bacia hidrográfica é a melhor unidade territorial do sistema ambiental, pois, representa claramente as interações entre o meio e o homem, evidenciado pelas diversas formas uso e ocupação do solo.

O uso inconsequente e sem devido planejamento ambiental, dentro de uma bacia hidrográfica, pode provocar a alteração dos sistemas ambientais componentes da bacia, causando impactos e perda da estabilidade e qualidade ambiental do sistema sendo que, considerando a unidade da bacia hidrográfica como um sistema aberto e que possui interação direta com suas sub-bacias e outras bacias hidrográficas adjacentes, promovendo o fluxo de energia e matéria, acarreta na mudança da forma como as bacias hidrográfica se relacionam. "[...] as bacias hidrográficas possibilitam uma visão de conjunto do comportamento das condições naturais e das atividades humanas nelas envolvidas, uma vez que mudanças significativas em qualquer dessas unidades podem gerar alterações, efeitos e/ou impactos significativos à jusante" (SILVA; CHAVES; FERREIRA, 2006, p. 03). Por isso, deve ser dada devida atenção aos diversos usos e ocupação dentro das bacias hidrográficas.

Mendonça (1999) enfatiza a importância dos estudos em bacias hidrográficas na temática ambiental, sendo que, é necessária uma cautelosa análise para a identificação da ocupação, considerada como os elementos naturais, e ao uso do solo, que são derivados das atividades humanas, pois, auxilia no reconhecimento e localização dos agentes responsáveis pelas atuais condições ambientais da área estudada. Santos; Ribeiro e Silva (2016) reiteram a importância dos estudos em bacias hidrográficas, sendo que é necessário "Conhecer o uso do solo em uma bacia hidrográfica e principalmente como se dá o funcionamento das atividades econômicas conduz a diagnósticos e prognósticos da área estudada" (p. 941942).

O Manual Técnico do Uso da Terra, disponibilizado pelo IBGE (Instituto Brasileiro de Geografia e Estatística - 2013), enfatiza que a cobertura e o uso da terra podem ser identificadas por meio de padrões homogêneos da cobertura, ou seja, áreas que possuem a mesma tipologia de cobertura do terreno. Com 


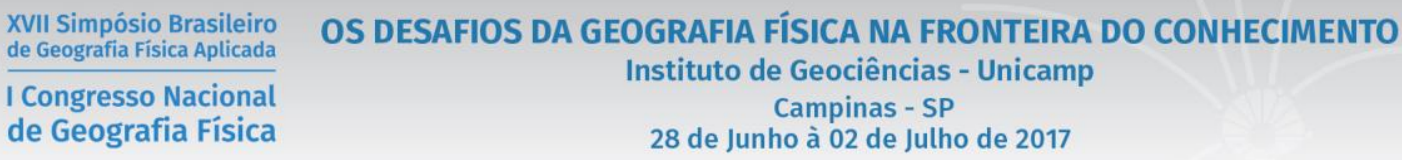

isso, uma bacia hidrográfica pode ser composta por vários mosaicos de tipologias homogêneas internos a esse polígono - área homogênea -, e diferente do polígono adjacente. Assim, variados polígonos constituem uma paisagem heterogênea.

Partindo da visão sistêmica em bacias hidrográficas, pode-se dizer que os elementos que compõem esse sistema, no caso as áreas homogêneas, possuem estreita relação entre si. Por exemplo, em uma área que está com o solo exposto, após um evento chuvoso, produzirá sedimentos que poderão ser carregados até o canal fluvial promovendo o assoreamento do rio, com isso, pode-se verificar que duas áreas homogêneas e divergentes ocupação direta. As

\section{Nível 1 - Classes} do Uso da Terra divididas em sendo $\quad 0 \quad 1^{\circ}$ classes, o $2^{\circ}$ subclasses e o unidades. relaciona níveis, o das os subclasses. quanto à possuem relação classes de uso, Manual Técnico (2013) são três níveis, concernente às relativo às $3^{\circ}$ nível o das quadro abaixo dois primeiros classes e o das

Quadro 1 - Classes e subclasses da classificação da cobertura e uso da terra 
Fonte: IBGE (2013), Org., PETRUCCI, E. (2017)

A partir do quadro 1, é possível verificar as diversas classificações dos tipos de cobertura e uso da terra em âmbito brasileiro. O terceiro nível, o das unidades, não foi reproduzido nesse trabalho por se tratar dos mais diversos tipos de tipologia que, em grande maioria, não compreende os usos e ocupação do solo verificados nesse trabalho.

Aplicadas técnicas de geoprocessamento para o mapeamento da cobertura e uso do solo, é possível verificar quais e quantas classes e subclasses determinada bacia hidrográfica pode compreender, além de análises e tratamento estatístico, podendo, por exemplo, serem calculadas o tamanho dessas áreas. "O levantamento sobre a Cobertura e o Uso da Terra comporta análises e mapeamentos e é de grande

utilidade para o conhecimento atualizado das formas de uso e de ocupação do espaço, constituindo importante ferramenta de planejamento e de orientação à tomada de decisão" (IBGE, 2013, p. 37).

Segundo Rosa (2005), há uma carência muito grande em mapeamentos no Brasil. Esse problema agrava para com os mapeamentos de uso e ocupação do solo, pois, o fator tempo deve ser levado em consideração. Ao longo do tempo pode ser observado diferentes usos dentro de uma mesma bacia hidrográfica, áreas naturais podem ser transformadas em pastagens ou destinadas à produção de culturas, pode ocorrer o abandono das terras e ocorrer a regeneração da vegetação, entre as mais diversas combinações. Um meio de facilitar a identificação e controle sobre os usos e ocupações em bacias hidrográficas pode ser por meio de técnicas de geoprocessamento porque, pode-se obter informações sobre uma área ou objeto sem a necessidade de contato físico com o (a) mesmo (a), por meio da radiação eletromagnética refletida ou emitida pelos alvos.

Verifica-se, portanto, que as ferramentas de Geoprocessamento constituem-se de instrumentos que fornecem subsídios para estudos ambientais, planejamento urbano e atividades que requeiram tomadas de decisões, promovendo uma avaliação das condições do meio ambiente, para que desta forma sejam articuladas ações preventivas e corretivas de manejo dos recursos naturais (Chuerubim; Pavanin, 2013, p. 231).

Nos últimos anos tem-se verificado a popularização da utilização das geotecnologias para estudos ambientais, mesmo frente ao elevado custo para a aquisição de softwares e capacitação dos usuários para o manuseio dessas ferramentas. Uma das alternativas para contornar os elevados custos de aquisição de 
softwares é o desenvolvimento e aplicação de softwares livres, como o Quantum Gis (Qgis), licenciado pelo GNU (General Public License). Segundo Torchetto et al. (2014) “A interface do software é simples e de fácil manuseio, o programa oferta várias ferramentas que possibilitam visualizar, gerenciar, editar, analisar os dados e compor mapas impressos, obter impressão com determinadas screenshots e uma lista de recursos mais detalhada (p. 712).

Santos; Ribeiro e Silva (2016) destacam que os "Fatores como gratuidade, precisão e acurácia na delimitação automática da rede de drenagem a partir de dados do SRTM em ambiente SIG, proporcionam economia de tempo e de recursos para a realização de pesquisas e diagnósticos ambientais" (p. 943). Com isso, mesmo que se deseja estudar uma bacia hidrográfica de difícil acesso ou que não tenha recursos necessários para o deslocamento e trabalhos de campo, é possível realizar estudos em gabinetes para a caracterização e análise sobre essas bacias.

A partir do geoprocessamento, pode-se obter informações sobre dados espaciais em que, o dado espacial retrata representações do mundo real em uma determinada escala e essas representações tem forma, cores

e localização. Com isso, o presente trabalho tem como objetivo a análise do uso e ocupação do solo, nas condições atuais, da bacia hidrográfica do Córrego Água Vermelha, no município de Uberlândia-MG, por meio do software livre Quantum Gis (Qgis).

\section{Delimitação da área de estudo e caracterização dos materiais e métodos}




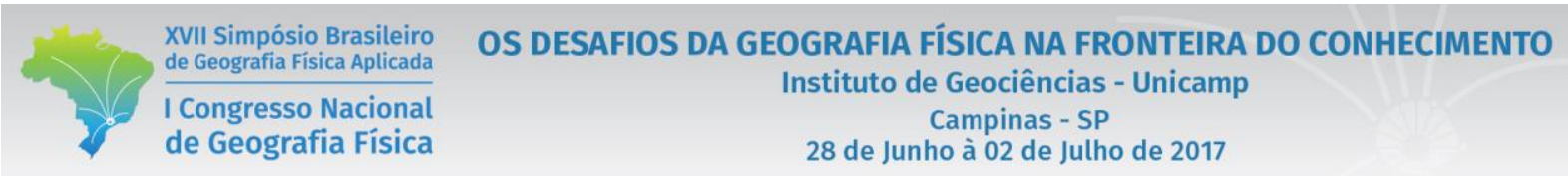

A Bacia do Córrego Água Vermelha localiza-se cerca de $16 \mathrm{Km}$ da área urbana, na região centro sul do município de Uberlândia-MG, que por sua vez encontra-se na mesorregião do Triangulo Mineiro / Alto Paranaíba (Figura 1). Seu limite concentra-se entre os pares de coordenadas $19^{\circ} 10^{\prime} \mathrm{S}$ de latitude e $48^{\circ} 30^{\prime} \mathrm{W}$ de longitude.

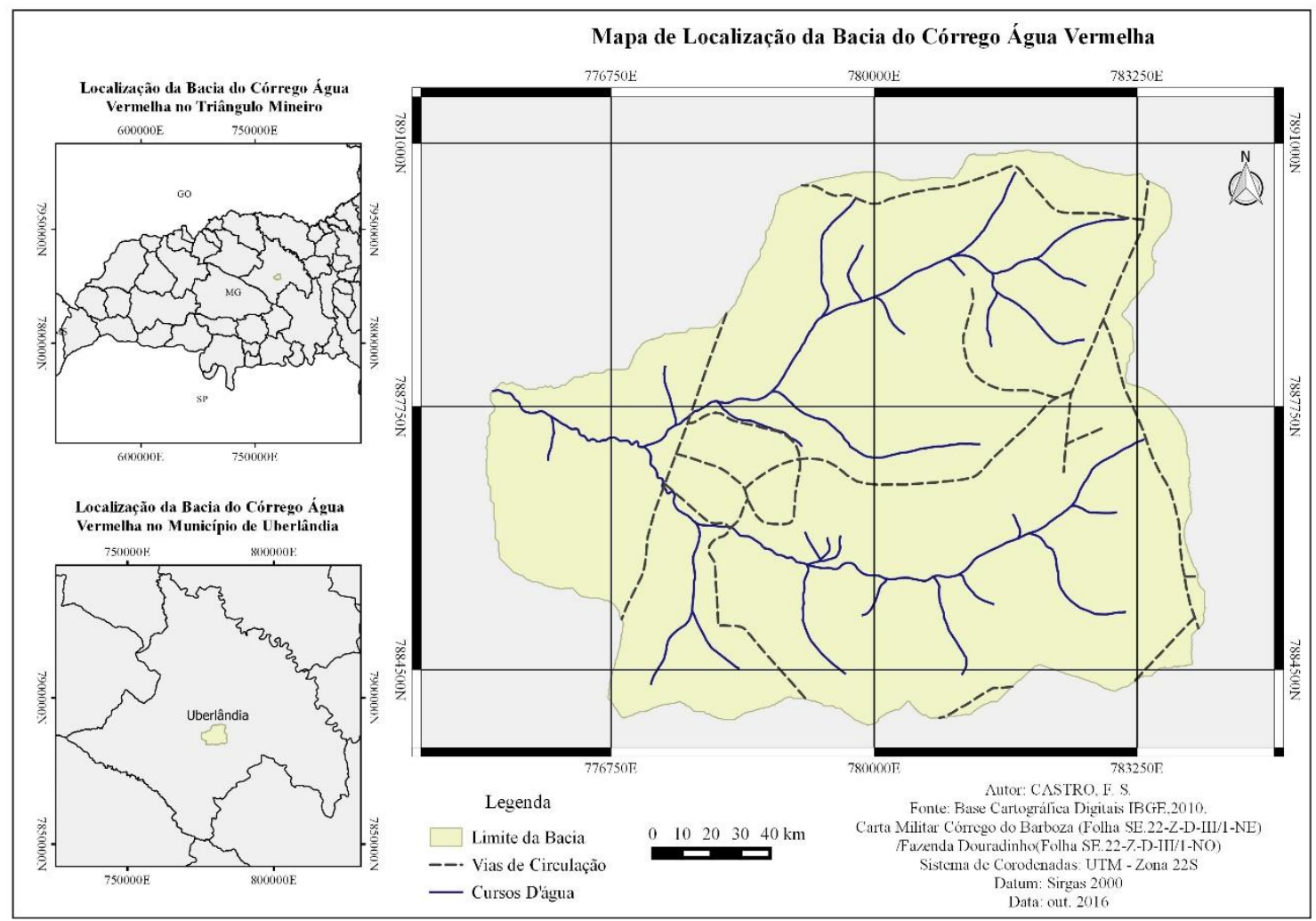

Figura 1 - Localização da Bacia do Córrego Água Vermelha (MG), 2017

Fonte: Instituto Brasileiro de Geografia e Estatística (IBGE), 2010. Org.: CASTRO, F.S. 2017.

Os aspectos climáticos vinculam-se ao regime do clima subquente úmido e semiúmido, com predominância de dias quentes ao longo do ano, com alternância entre meses mais secos, de maio a

setembro (inverno), e os mais chuvosos de outubro a abril (verão). A temperatura média concentra-se por volta dos $21^{\circ} \mathrm{C}$ e pluviosidade entre $1250 \mathrm{~mm}$, concentrando $1800 \mathrm{~mm}$ no verão. (NOVAIS, 2011).

A área abordada está inserida na porção dos Domínios dos Chapadões Tropicais do Brasil Central (RADAM-BRASIL, 1983), como áreas de Planaltos e Chapadas da bacia sedimentar do Paraná. A 


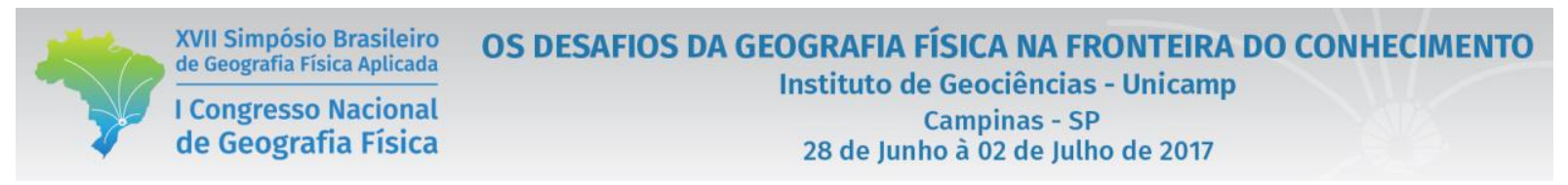

presença de arenitos da Formação Marília caracteriza a área, com vertentes convexas, topos planos e baixos entalhamentos da drenagem.

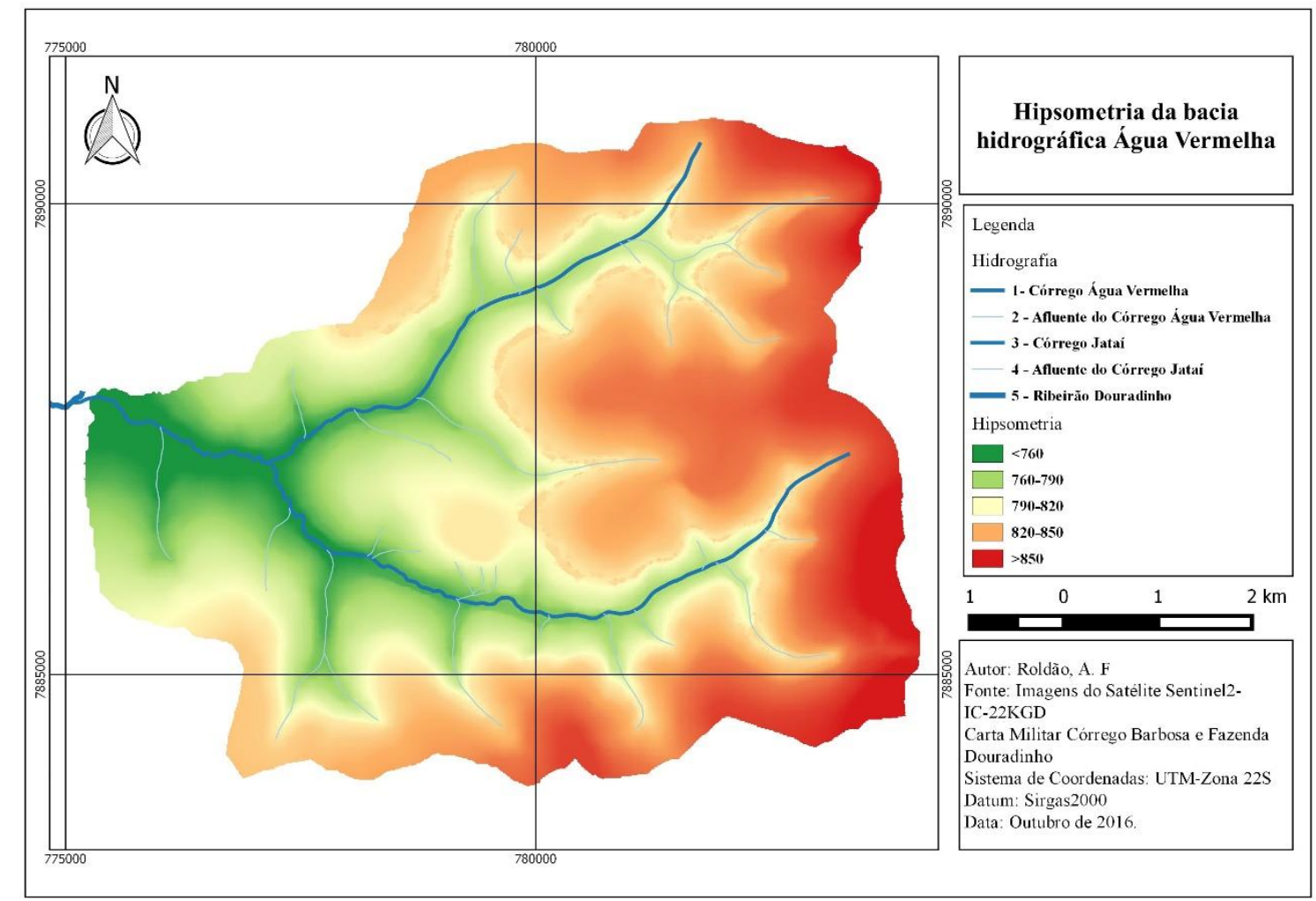

Figura 2 - Hipsometria da Bacia do Córrego Água Vermelha, 2016.

Fonte: Imagens do Satélite Sentinel 2. Org. ROLDÃO. A. F. 2016.

A bacia é constituída por dois cursos principais, o Córrego Água Vermelha e o Córrego Jataí, a mesma apresenta altitude mínima menor que $770 \mathrm{~m}$, que acompanham o percurso dos córregos da foz ao médio curso, correspondendo as planícies aluviais, nestas regiões as variações de declividade vão de $0 \%$ a $5 \%$, onde as classes de relvo vão de plano a suave ondulado, segundo a classificação de Lepsh (1991) e EMBRAPA (1979), (Figura 2). Avançando para as bordas das chapadas, no curso superior, encontram-se áreas que alcançam altitude máxima de $863 \mathrm{~m}$ nas nascentes do Córrego Água Vermelha e é também nestes pontos, no contato da chapada com o relevo dissecado que os registros de declividade são mais

elevados, registrando até $15 \%$ de declividade, relevo moderadamente ondulado. A presença de voçorocas é marcante nesse recorte do ambiente (Figura 3). 

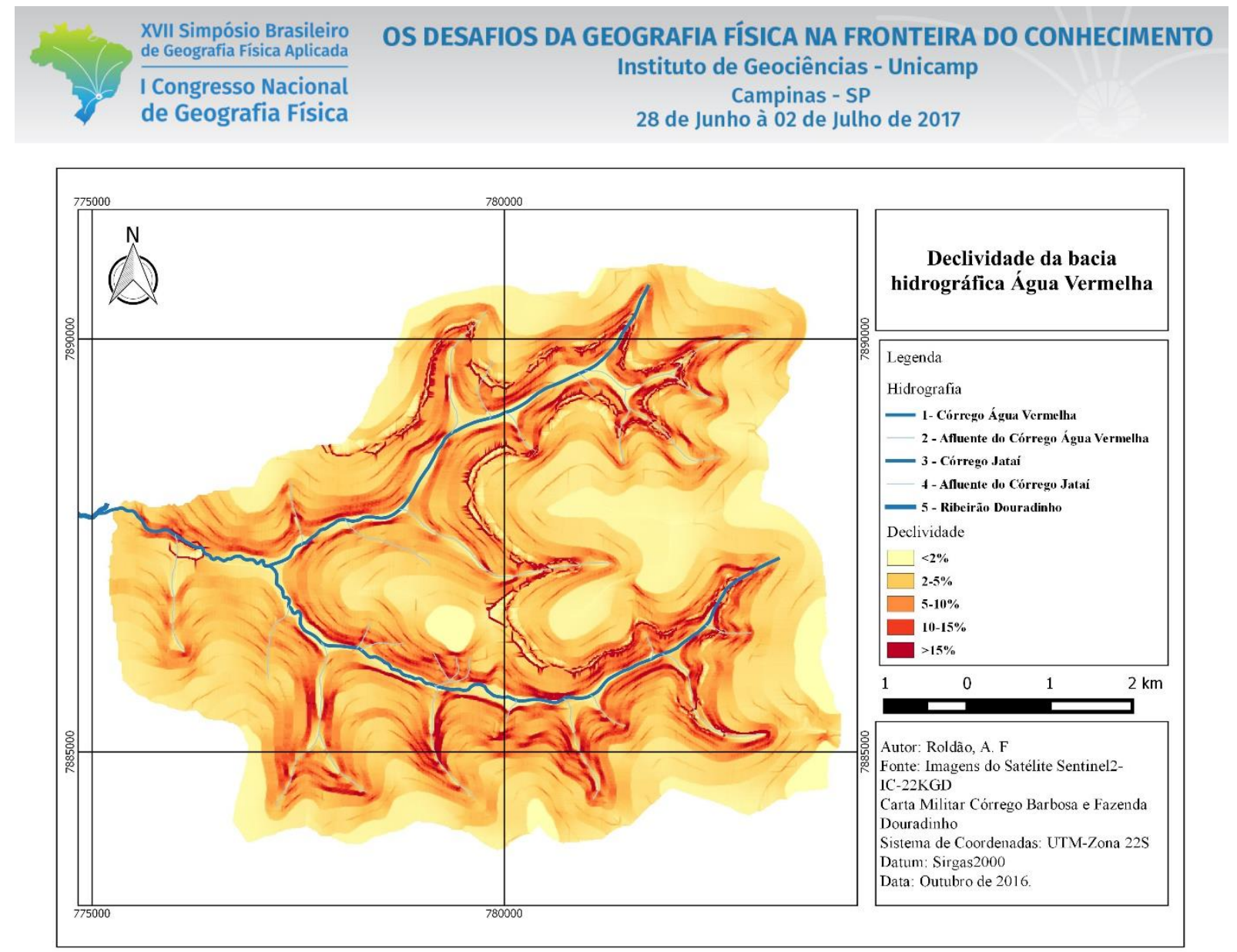

Figura 3 - Declividade da Bacia do Córrego Água Vermelha, 2016.

Fonte: Imagens do Satélite Sentinel 2. Org. Org. ROLDÃO. A. F. 2016

Intuindo alcançar o objetivo proposto pelo trabalho, houve a divisão do mesmo em três etapas: $1^{\text {a }}$ delimitação da área de estudo; $2^{\mathrm{a}}$ revisão bibliográfica acerca do tema pretendido e $3^{\mathrm{a}}$ escolha e aplicação dos métodos de mapeamento. A última etapa do processo de construção do artigo, foram escolhidas ferramentas do software QGIS, versão 2.8. O passo a passo consistiu no georreferenciamento das cartas topográficas, Córrego do Barbosa (Folha SE.22-Z-D-III-1-NE) e Fazenda Douradinho (Folha SE.22-Z-DIII-1-NO), ambas disponibilizadas pelo Ministério do Exército Brasileiro, com escala de 1:25.000 e sob referencial geodésico Datum SAD 69.

Confecção do mosaico, recorte e delimitação da bacia escolhida (Bacia do Córrego Água Vermelha), transformadas para o sistema de projeção vigente (SIRGAS 2000) e extração da drenagem e das vias de circulação local. Após as etapas inicias de delimitação da área, seguiu-se para confecção do mapa de uso

do solo, para tanto, foi adquirido, junto ao catálogo da Agência Espacial Europeia (ESA), uma imagem do Satélite Sentinel2 - 1C-22KGD do ano de 2016, com composição colorida (RGB) delimitada pela 
combinação das bandas 04,03 e 02 e resolução de $10 \mathrm{~m}$. A partir dessa imagem foi possível recortar, através da camada vetorial construída em etapas anteriores, a área da bacia e extrair pelo método de seleção de feições as classes de uso identificadas.

\section{Resultados e discussões}

A partir da delimitação dos polígonos e identificação das classes e subclasses de uso e ocupação do solo correspondente, foi possível elaborar o mapa de uso do solo da bacia hidrográfica do Córrego Água Vermelha. Foi objetivado analisar quantitativamente quais as classes de uso e ocupação que é admitido na bacia e as porcentagens que cada classe representa no total da cobertura da superfície do solo. As classes identificadas foram: áreas de vegetação natural, área antrópica agrícola e área antrópica não agrícola (quadro 2).

Quadro 2 - Classes e subclasses de uso e ocupação do solo e amostra na imagem

\begin{tabular}{|c|c|c|c|c|c|c|c|c|}
\hline & \multicolumn{2}{|c|}{$\mathbf{1}^{\mathrm{a}}$} & \multicolumn{2}{|c|}{$2^{a}$} & \multicolumn{2}{|c|}{$3^{a}$} & \multicolumn{2}{|c|}{$4^{a}$} \\
\hline & Classe & Subclasse & Classe & Subclasse & Classe & Subclasse & Classe & Subclasse \\
\hline & $\begin{array}{c}\text { Área de } \\
\text { vegetação } \\
\text { natural }\end{array}$ & $\begin{array}{c}\text { Área } \\
\text { florestal e } \\
\text { campestre }\end{array}$ & $\begin{array}{c}\text { Área } \\
\text { antrópica } \\
\text { agrícola }\end{array}$ & Pastagem & $\begin{array}{c}\text { Área } \\
\text { antrópica } \\
\text { agrícola }\end{array}$ & $\begin{array}{l}\text { Cultura } \\
\text { temporária }\end{array}$ & $\begin{array}{c}\text { Área } \\
\text { antrópica } \\
\text { não agrícola }\end{array}$ & $\begin{array}{c}\text { Área } \\
\text { urbanizada }\end{array}$ \\
\hline $\begin{array}{c}\text { Amostra } \\
\text { da } \\
\text { imagem }\end{array}$ & & & & & & & & \\
\hline
\end{tabular}

Fonte: Imagem Sentinel2 - 1C-22KGD

Org: CASTRO, F. S. (2017)

De acordo com o quadro 2, a primeira classe verificada foi a de Área de vegetação natural e, foram identificados dois tipos de subclasses, área florestal e área campestre. A segunda e a terceira classes identificadas foram Área antrópica agrícola, com a subclasse pastagem e cultura temporária, respectivamente. A quarta classe encontrada foi Área antrópica não agrícola, com a subclasse área urbanizada. Nesse caso, a área urbanizada são construções para moradia, em pontos isolados da bacia.

Entretanto, apesar de terem sido encontradas as classes e subclasses acima referidas, consensualmente, não são verificadas essas terminologias em trabalhos e mapas de uso e ocupação do solo. Com isso, a $1^{\mathrm{a}}$ classe (área de vegetação natural) foi denominada Vegetação; a $2^{\mathrm{a}}$ classe (Área antrópica agrícola) foi denominada de Pastagem. A $3^{\mathrm{a}}$ classe (Área antrópica agrícola) ficou como Agricultura e a $4^{\mathrm{a}}$ classe (Área 


\section{OS DESAFIOS DA GEOGRAFIA FÍSICA NA FRONTEIRA DO CONHECIMENTO \\ Instituto de Geociências - Unicamp \\ Campinas - SP \\ 28 de Junho à 02 de Julho de 2017}

antrópica não agrícola) como Edificações. Após a identificação das classes e subclasses, foi possível gerar o mapa de uso e ocupação da bacia hidrográfica do Córrego Água Vermelha (Figura 4).

De acordo com a Figura 4, é possível verificar a predominância das classes agricultura e pastagem em detrimento das classes vegetação e edificações. Dito isso, é possível perceber um elevado grau de intervenções antrópicas na referida bacia, ou seja, o uso do solo é maior do que a ocupação.

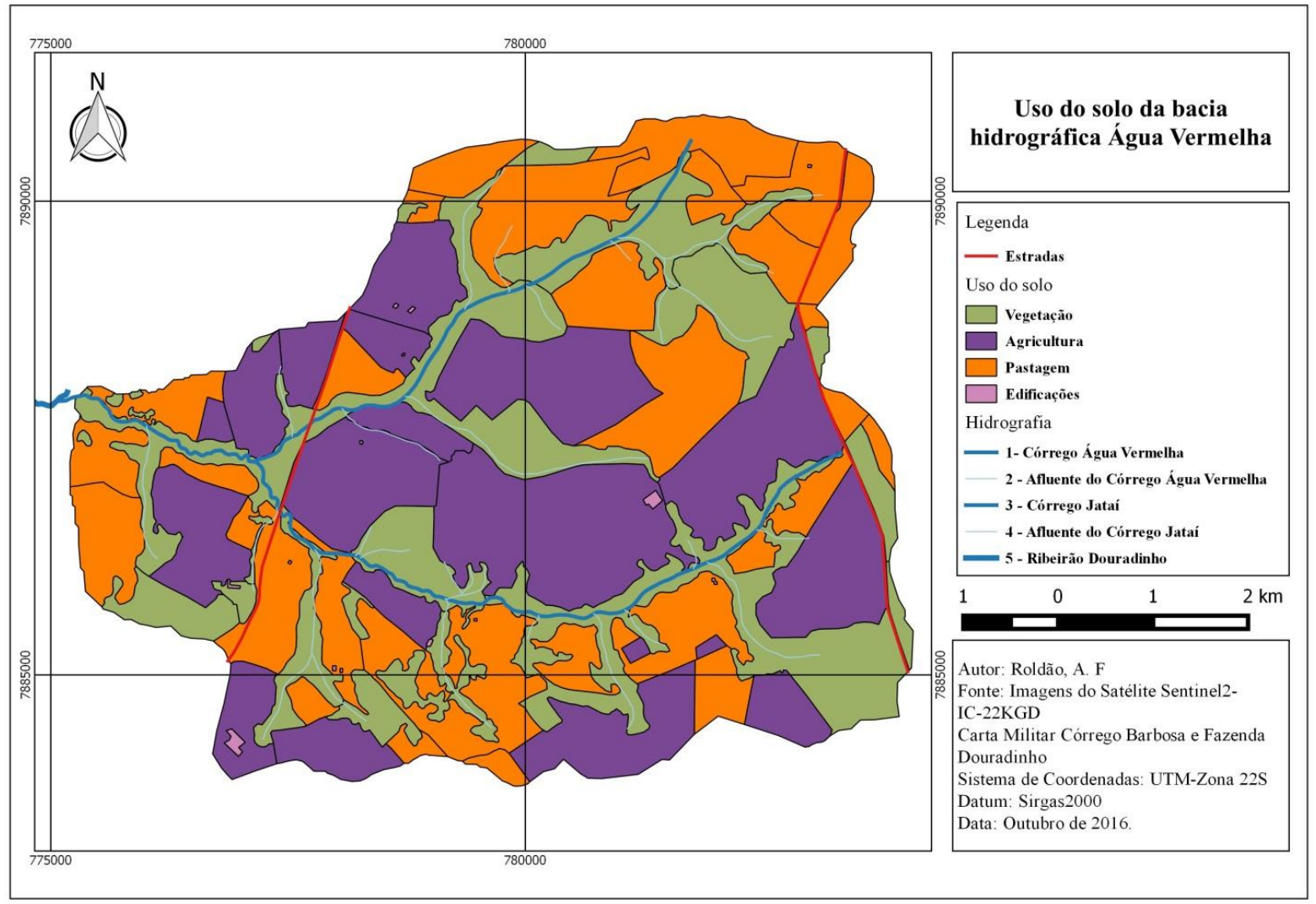

Figura 4 - Uso do solo da Bacia do Córrego Água Vermelha, 2016 Fonte: Imagens do Satélite Sentinel 2. Org. ROLDÃO. A. F. 2016.

A tabela 1 relaciona os valores estatísticos de cada classe, os valores absolutos, em $\mathrm{km}^{2}$ e suas respectivas porcentagens de cobertura em relação ao total.

De acordo com a tabela 1, as áreas de agricultura representam a maior porcentagem de uso do solo da bacia, sendo de 52,1\%, ou seja, mais da metade da área da bacia é utilizada para as práticas agrícolas, principalmente de culturas temporárias. Em seguida, as áreas de pastagem, representando o segundo maior uso do solo da bacia, com $0,473850 \mathrm{~km}^{2}$, o equivalente a 40,5\% da área total. Já as áreas de vegetação 
ocupam apenas uma porcentagem de $7,1 \%$ da bacia, o que demonstra um intenso processo de degradação, provocado principalmente pelas práticas agropecuárias.

Tabela 1 - Análise quantitativa do uso e ocupação do solo da Bacia do Córrego Água Vermelha.

\begin{tabular}{ccc}
\hline \multirow{2}{*}{ Classe } & \multicolumn{2}{c}{ Área Ocupada } \\
\cline { 2 - 3 } & $\mathbf{K m}^{\mathbf{2}}$ & $\mathbf{\%}$ \\
\hline Vegetação & 0,083127 & 7,1 \\
\hline Agricultura & 0,608972 & 52,1 \\
\hline Pastagem & 0,473850 & 40,5 \\
\hline Edificações & 0,002806 & 0,2 \\
\hline Área Total & $\mathbf{1 , 1 6 8 7 5 5}$ & $\mathbf{1 0 0}$ \\
\hline & \multicolumn{2}{c}{ Org: ROLDÃO, A. F. (2017) }
\end{tabular}

A menor porcentagem de uso do solo na bacia é a da classe das edificações, ocupando uma área de $0,002806 \mathrm{~km}^{2}$, o que equivale a apenas $0,2 \%$ da bacia do Córrego Água Vermelha.

Aproximadamente 93\% da área total da bacia do Córrego Água Vermelha é caracterizada por processos de antropização, o que gera intensos impactos ambientais na mesma, como por exemplo, o desmatamento, o qual é responsável pela erosão do solo e por um desequilíbrio ecológico no local. Desta forma, faz-se necessário um equilíbrio entre os sistemas produtivos e a forma de utilização dos recursos naturais.

\section{Considerações Finais}

De acordo com o mapa de uso e ocupação do solo da bacia do Córrego Água Vermelha, é possível verificar que há mais áreas antropizadas do que áreas naturais, na proporção de, aproximadamente 93\% da área com algum tipo de uso do solo e 7\% para áreas de ocupação natural. Do total da área antropizada, mais da metade é dedicada à produção agrícola, com predominância da subclasse cultura temporária, e a outra grande parte é dedicada à pecuária, representado pelas pastagens.

Apenas 7,1\% da área da bacia é ocupada por vegetação, que se restringe, basicamente, às matas ciliares e áreas de preservação permanente. A baixa porcentagem de vegetação traz à tona preocupações concernentes ao equilíbrio ambiental da bacia, devido à grande importância que ela admite, como por exemplo, retenção de água no subsolo, promoção de estabilidade dos agregados do solo e manutenção do ecossistema em geral. Relacionando a vegetação com a declividade da bacia, é verificado que a maior parte da vegetação se encontra nas margens dos canais fluviais, sendo que, essas áreas possuem declividade menor que $2 \%$. O predomínio da vegetação vai se estendendo até em áreas maior que $15 \%$, 
de forma não-linear. Entretanto, as áreas de 10-15\% de declividade percebem baixa concentração de vegetação nativa, podendo acelerar processos de assoreamento do canal fluvial e promover processos erosivos.

As áreas edificadas caracterizam a menor tipologia de uso verificado e são bem dispersas ao longo da bacia. As áreas destinadas à produção agrícola somam 52,1\% do total da bacia e elas estão concentradas nas classes $2-5 \%$ e $5-10 \%$ de declividade. Entretanto, é necessária a realização de trabalhos de campo para especificar e determinar o $3^{\circ}$ nível de classificação da cobertura e uso do solo (nível das Unidades), segundo o Manual Técnico de Uso da Terra, que são os tipos de cultura que são produzidos na bacia.

Por fim, foi possível verificar que o software Qgis foi uma ótima ferramenta para o mapeamento do uso e ocupação do solo da bacia estudada. Com isso, reitera-se a utilização de softwares livres para a produção cartográfica.

\section{Referências bibliográficas}

BRASIL. Constituição (1997). Lei no 9433, de 08 de janeiro de 1997. Institui a Política Nacional de Recursos Hídricos, cria o Sistema Nacional de Gerenciamento de Recursos Hídricos, regulamenta o inciso XIX do art. 21 da Constituição Federal, e altera o art. $1^{\circ}$ da Lei n ${ }^{\circ} 8.001$, de 13 de março de 1990, que modificou a Lei n ${ }^{\circ} 7.990$, de 28 de dezembro de 1989. Lei No 9.433, de 8 de Janeiro de 1997: Lei Federal. 1. ed. Brasília, DF, 08 jan. 1997. Disponível em <http://www.planalto.gov.br/ccivil_03/leis/L9433.htm>, acesso em 08 de Março de 2017.

CHUERUBIM, Maria Lígia; PAVANIN, Erich Vectore. Análise do uso e ocupação do solo na bacia hidrográfica do Córrego Barbosa no ano de 2011. GEOUSP - espaço e tempo, São Paulo, n. 33, p. 229-238, 2013.

CUNHA, Sandra Baptista da. Sistemas ambientais de grandes rios: degradação e recuperação. In: SILVA, José Borzacchiello da; LIMA, Luiz Cruz e ELIAS, Denise (org.). Panorama da geografia brasileira, v. 1. São Paulo: Annablume, 2006.

EMPRESA BRASILEIRA DE PESQUISA AGROPECUÁRIA - EMBRAPA. Serviço Nacional de Levantamento e Conservação de Solos (Rio de Janeiro, RJ). Súmula da $10^{\mathbf{a}}$ Reunião Técnica de Levantamento de Solos. Rio de Janeiro, 1979. 83p.

INSTITUTO BRASILEIRO DE GEOGRAFIA E ESTATÍSTICA (IBGE). Manual Téenico de Uso da Terra. 3 ed. Rio de Janeiro, 2013. Disponível em: <http://biblioteca.ibge.gov.br/visualizacao/livros/liv81615.pdf>. Acesso em: 09 de Março de 2017.

INSTITUTO BRASILEIRO DE GEOGRAFIA E ESTATÍSTICA (IBGE). Mapas. Disponível em: $<$ http://mapas.ibge.gov.br/bases-e-referenciais > Acesso em: outubro de 2016. 
LEPSCH, I.F.; BELLINAZZI Jr., R.; BERTOLINI, D.; ESPÍNDOLA, C.R. Manual para levantamento utilitário do meio físico e classificação de terras no sistema de capacidade de uso. $4^{\text {a }}$ Aproximação. $2^{\mathrm{a}}$. ed. Campinas: Sociedade Brasileira de Ciência do Solo, 1991.175p.

MENDONÇA, Francisco de Assis. Diagnóstico e análise ambiental em microbacia hidrográfica: proposição metodológica na perspectiva do zoneamento, planejamento e gestão ambiental. RA'EGA, v. 3, p. 67-89, 1999. Disponível em: <http://revistas.ufpr.br/raega/article/view/18225/11822>, acesso em 06 de Março de 2017.

NOVAIS, G. T. Caracterização climática da mesorregião do Triângulo Mineiro/Alto Paranaíba e do entorno da Serra da Canastra (MG). 2011. 175 f. Dissertação (Mestrado) - Curso de Mestrado em Geografia, Instituto de Geografia, Universidade Federal de Uberlândia, Uberlândia, 2011. Cap. 3.

RADAM-BRASIL. Ministério das Minas e Energia. Secretaria Geral. Levantamento de Recursos Naturais, Rio de Janeiro, p. Folha SE, 22 Goiânia, 1983.

ROSA, Roberto. Geotecnologias na geografia aplicada. Revista do Departamento de Geografia. v. 16, 2005, p. 8190.

SANTOS, Leonardo Lima dos; RIBEIRO, Vinícius de Oliveira; SILVA, João Lucas Alves da. Aplicação de geotecnologias gratuitas e livres na delimitação e análise do uso e cobertura do solo na Bacia Hidrográfica do córrego Laranja Doce. In: Simpósio de Geotecnologias do Pantanal, 6, 2016, Cuiabá-MT, Anais $6^{\circ}$ Simpósio de Geotecnologias no Pantanal, Anais, 2016, p. 936-945.

TORCHETTO, Natieli Luisa; et. al., O uso do Quantum Gis (QGIS) para caracterização e delimitação de área degrada por atividade de mineração de basalto no município de Tenente Portela (RS). Revista Eletrônica em Gestão, Educação e Tecnologia Ambiental - REGET. v. 18. n. 2, maio-ago 2014, p. 719-726. 